\title{
PROGAME - Ambiente Gamificado para Simulação do Exame SPAECE
}

\author{
Francisco Aislan da Silva Freitas ${ }^{1}$, Paulo Henrique Mendes Maia ${ }^{1}$, Jezmael Oliveira Basílio ${ }^{2}$ \\ ${ }^{1}$ Universidade Estadual do Ceará (UECE) \\ Fortaleza - CE - Brasil \\ ${ }^{2}$ Universidade do Estado do Rio Grande do Norte(UERN) \\ Mossoró - RN - Brasil \\ \{aislansf, jezmaelbasilio\}@gmail.com, pauloh.maia@uece.br
}

\begin{abstract}
Gamification can be used as an interaction strategy that can stimulate the engagement of the public involved. This article presents the ProGame, a gamified environment that allows students to train through challenges for the mathematics tests of the Permanent System of Evaluation of Basic Education of Ceará (SPAECE). The usability of the environment was validated by 34 students of a class of the first year of high school in a state school in Ceará.
\end{abstract}

Resumo. Gamificação pode ser utilizada como uma estratégia de interação que pode estimular o engajamento do público envolvido. Este artigo apresenta o ProGame, um ambiente gamificado que permite estudantes treinarem por meio desafios para as provas de matemática do Sistema Permanente de Avaliação da Educação Básica do Ceará (SPAECE). A usabilidade do ambiente foi validada por 34 alunos de uma turma do $1^{\circ}$ ano do ensino médio de uma escola estadual do Ceará.

\section{Introdução}

Atualmente, as Tecnologias Digitais de Informação e Comunicação (TDIC) oferecem aos profissionais da educação estratégias essenciais para um melhor desempenho dos alunos no contexto escolar. Com o rápido avanço dessa área, é comum encontrar e utilizar diversos recursos educacionais, como softwares educativos e objetos de aprendizagem, para diferentes meios digitais, como computadores, tablets e smartphones, proporcionando novas alternativas de ensino e aprendizagem.

Com isso, uma abordagem crescente é a utilização de jogos educativos para ensino de diversas disciplinas [Moratori 2003] . Dentro dos jogos pode-se trabalhar tanto as habilidades psicomotoras, como raciocínio lógico, quanto também as sociais, por meio de interação com outros jogadores. Estudos mostram que o uso de jogos educativos no ambiente escolar melhora a aprendizagem na medida em que complementam o processo de ensino tradicional [Alves 2015][Neto et al. 2015]. Além do uso de jogos educativos, o processo de gamificação, que aplica elementos e técnicas de design de games a vivências e contextos não caracterizados como games [Fardo 2014], vem sendo cada vez mais utilizado com sucesso como ferramenta importante para a aprendizagem [Alves 2015][Borges et al. 2013][Seixas et al. 2014][Neto et al. 2015].

Este trabalho propõe um ambiente gamificado, chamado ProGame, para que alunos do 10 ano do ensino médio possam se preparar para o Sistema Permanente de 
VIII Congresso Brasileiro de Informática na Educação (CBIE 2019)

Anais dos Workshops do VIII Congresso Brasileiro de Informática na Educação (WCBIE 2019)

Avaliação da Educação Básica do Ceará ${ }^{1}$ (SPAECE), que avalia as escolas públicas das redes estaduais e municipais do estado do Ceará nas disciplinas de língua portuguesa e matemática. O SPAECE aplica provas para avaliar os conhecimentos dos alunos nesses assuntos, permitindo que as escolas possam visualizar, através de indicadores, a evolução dos seus alunos nessas matérias, e o estado possa acompanhar o desempenho das escolas e monitorar se os níveis de aprendizagem estão dentro dos parâmetros de qualidade educacional por ele definidos. O ambiente aqui proposto contempla apenas o conteúdo de matemática e permite aos professores criarem desafios de diferentes níveis para os alunos treinarem e competirem entre si utilizando mecanismos como ranking, pontuação, e premiação, dentre outros.

O restante deste trabalho está dividido nas seguintes seções: a seção 2 discute os principais conceitos relacionados à gamificação, enquanto na seção 3 são descritas as principais funcionalidades do ProGame. Na seção 4 são mostrados os resultados da avaliação de usabilidade dos alunos usuários do ambiente gamificado. Por fim, na seção 5 são expostas as considerações finais.

\section{O Amibiente Gamificado ProGame}

Para o desenvolvimento do ProGame, foram utilizadas as seguinte tecnologias: CSS, JavaScript, HTML 5, PHP e MySQL. O ProGame está sob licença do tipo Creative Commons CC BY 4.0 e poderá ser aplicado em sala de aula utilizando projetores, smartphones e PC's.

O ambiente gamificado ProGame possui quatro atores principais: Administrador do sistema, Escola, Professor e Aluno. Cada ator possui funcionalidades específicas no ambiente, podendo algumas delas ser aplicadas a outro ator. O Ator Administrador do sistema possui as funcionalidades de adicionar, remover, atualizar, pesquisar e listar as escolas. Para cada escola serão atribuídas credenciais de acesso ao ambiente ProGame (logins e senhas), que permitem a escola entrar no ambiente.

$\mathrm{O}$ ator Escola pode acessar as seguintes funcionalidades: adicionar, remover, atualizar, pesquisar e listar cursos, disciplinas, turmas e professores. Os cursos dizem respeito aos oferecidos pelas escolas profissionalizantes e abrangem diversas áreas como Ambiente e Saúde, Controle e Processos Industriais, Gestão e Negócios, dentre outros. A escola pode adicionar qualquer disciplina, mas o foco principal do ambiente é abordar, inicialmente, a matemática, que é uma das disciplinas avaliadas no SPAECE.

Adicionados os cursos e as disciplinas, a escola cadastrará as turmas do $1^{\circ}, 2^{\circ} \mathrm{e}$ $3^{0}$ ano no ambiente, sendo cada turma associada a um curso e ano de início da mesma. Por fim, a escola adiciona os professores, preenchendo os principais dados como nome, disciplina que ministra, a turma que leciona, e-mail principal de acesso, login de acesso ao sistema e a senha de acesso. Outras funcionalidades da escola são visualizar a quantidade de acessos dos alunos ao ambiente, listar alunos cadastrados, perguntas adicionadas e desafios gerados pelos professores.

Já os professores com suas credenciais podem: adicionar, remover, atualizar, pesquisar e listar alunos, perguntas, desafios e conquistas. Ao adicionar as perguntas, o professor deve preencher as informações a seguir: selecionar a disciplina, informar o

\footnotetext{
${ }^{1}$ http://www.spaece.caedufjf.net/
} 
VIII Congresso Brasileiro de Informática na Educação (CBIE 2019)

Anais dos Workshops do VIII Congresso Brasileiro de Informática na Educação (WCBIE 2019)

enunciado da pergunta, adicionar imagem de apoio (se necessário), adicionar os itens da pergunta e indicar qual dos itens é o correto. Ao final o professor pode atribuir pontos à cada questão adicionada, permitindo informar o valor dos pontos em um intervalo de 1 a 100, sendo que a pontuação menor representa uma questão fácil, enquanto a maior pontuação representa uma questão muito difícil. Com as perguntas adicionadas, o professor poderá criar novos desafios para ser respondido por seus alunos.

Para adicionar um novo desafio, o professor deve informar o nome do desafio, considerado como título do desafio, selecionar a qual turma será direcionado o desafio, selecionar a disciplina do desafio (caso o professor ministre mais de uma) e descrever de forma sucinta os objetivos do desafio gerado pelo professor. Para se concluir o cadastro do desafio, será necessário adicionar no mínimo 5 perguntas e preencher as informações supracitadas. Fica a critério do professor adicionar insígnias (conquistas) por desafio, que é um dos mecanismos da gamificação implementados no ambiente e pode motivar os alunos para chegar até o fim do desafio.

Os alunos com as suas credenciais possuem acesso a Ranking,editar seu perfil, visualizar desafios disponíveis, participar de fóruns, visualizar quadro de conquistas, visualizar seu desempenho geral e acompanhar seu nível de desempenho na plataforma. A tela inicial do aluno exibe o ranking do aluno em relação aos pontos obtidos nos desafios, indicando a posição do mesmo em comparação com os alunos da escola, turma ou curso. A funcionalidade visualizar desafios é listar todos os desafios da turma, caso o aluno deseje responder um dos desafios, basta apenas clicar no desafio desejado. Um relógio contabiliza o tempo que o aluno leva para responder o desafio. Quando o aluno finaliza o desafio, ele visualiza seu desempenho seja no formato de gráfico ou textual, indicando percentual de acerto e erro, pontos obtidos, tempo e data de conclusão do desafio.

Outros elementos de gamificação existentes no ProGame são: feedback de quais questões o aluno acertou e errou, e insígnias, caso o professor tenha adicionado aíguma conquista ao desafio. Se o aluno necessitar se preparar para responder os desafios, o mesmo pode utilizar a opção do fórum para montar um espaço de discussão entre os alunos e trocar ideias entre os participantes. O nível de desempenho do aluno é composto pelo total de pontos obtidos nos desafios e é representado como uma escala de 1 a 100, sendo considerado o nível 1 como iniciante na plataforma, ou seja, um aluno que respondeu poucos desafios, podendo chegar ao nível 100, que é considerado como um aluno que já respondeu muitos desafios.

A Figura 1 representa a interface gráfica dos desafios do aluno. Nessa tela são aplicados três elementos da gamificação: o primeiro é o LeadBoard, que é representado pelo ranking dos 20 primeiros alunos que obtiveram mais pontos nos desafios respondidos. Esse ranking agrega o segundo elemento da gamificação, a competitividade, que estimula os alunos a obter mais pontos nos desafios. Por fim, o terceiro elemento é a mudança de nível, que indica a experiência do aluno no ambiente ProGame.

A Figura 2 mostra um exemplo do ambiente de respostas dos desafios, contendo as questões selecionadas pelos professores, exibindo o nome do desafio que está sendo respondido, o tempo decorrente do desafio, quantas questões restam para concluir, o enunciado da questão e os itens de cada questão. 
VIII Congresso Brasileiro de Informática na Educação (CBIE 2019)

Anais dos Workshops do VIII Congresso Brasileiro de Informática na Educação (WCBIE 2019)

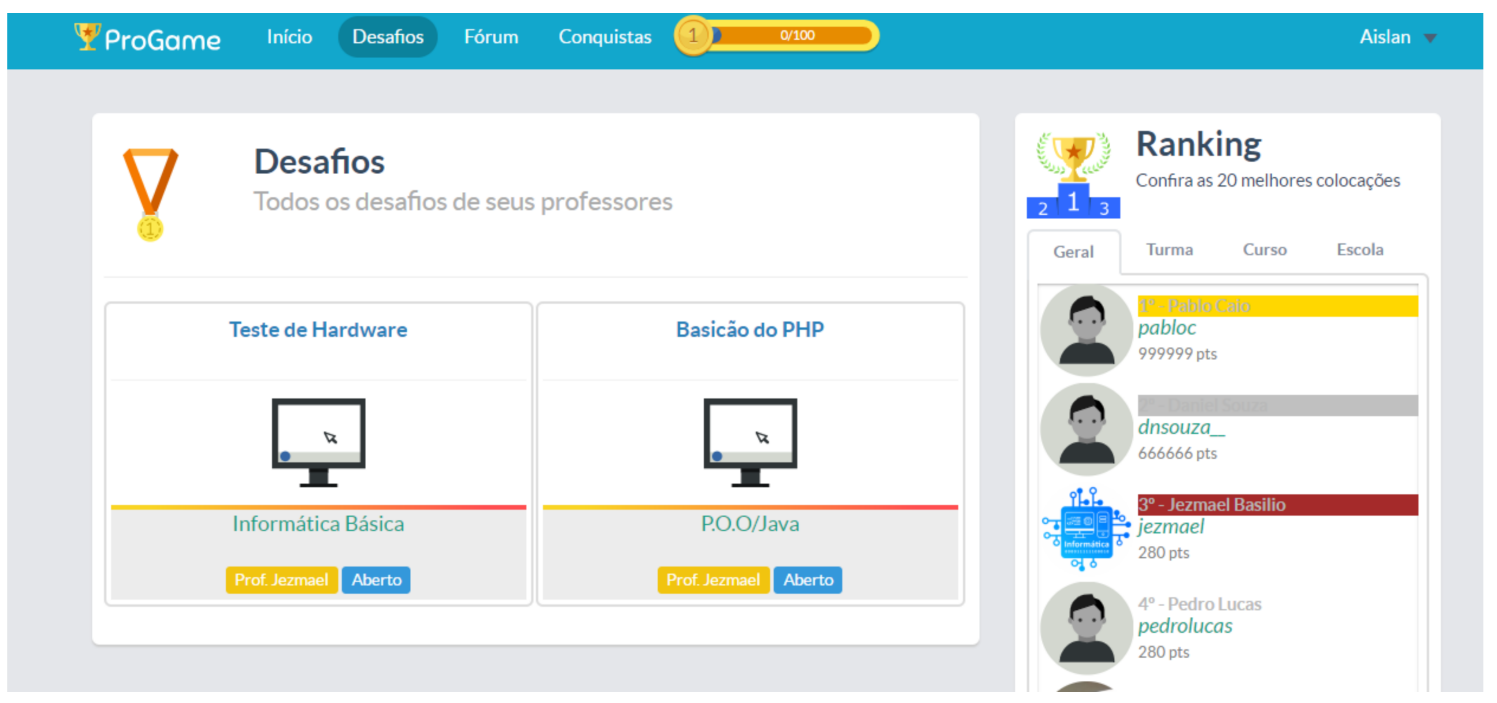

Figura 1. Tela dos desafios dos alunos

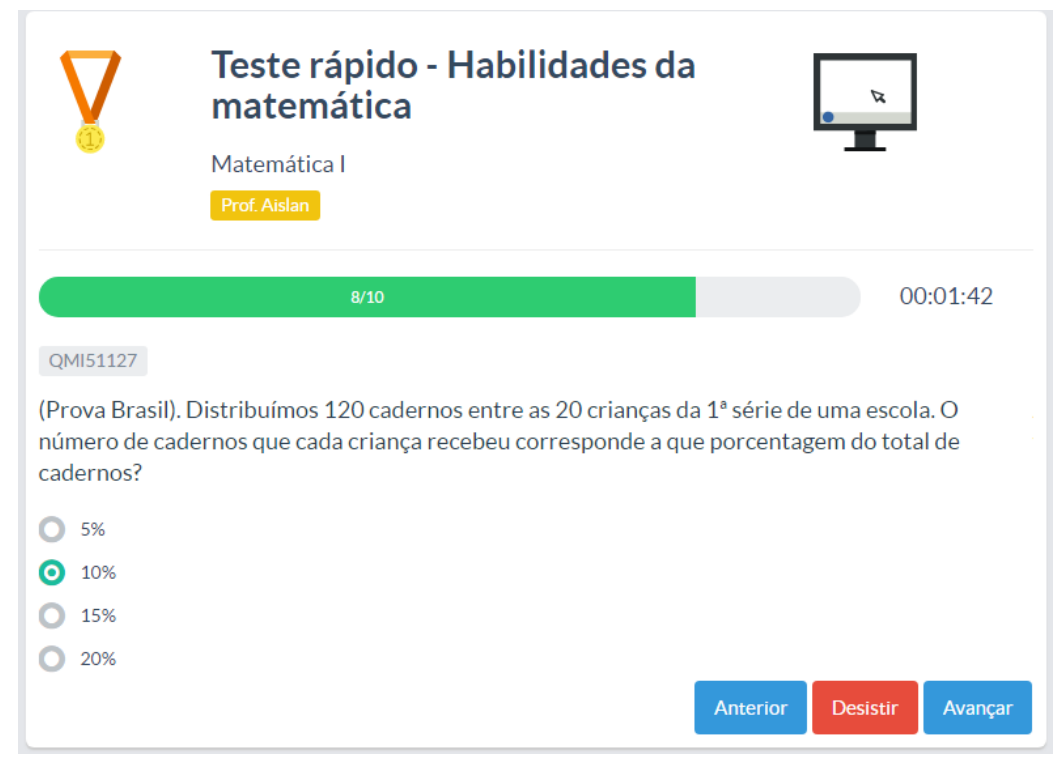

Figura 2. Exemplo da janela de respostas dos desafios

Ao final de cada desafio respondido é gerado um gráfico apresentando o desempenho do aluno, quantas questões o aluno acertou e quantas o mesmo errou no desafio, conforme ilustrado na Figura 3. Nessa janela são aplicados dois elementos da gamificação: O feedback instantâneo, indicando as questões corretas e as erradas, e a divulgação do mérito, por meio da qual o aluno ganha a insígnia adicionada pelo professor no desafio. 
VIII Congresso Brasileiro de Informática na Educação (CBIE 2019)

Anais dos Workshops do VIII Congresso Brasileiro de Informática na Educação (WCBIE 2019)

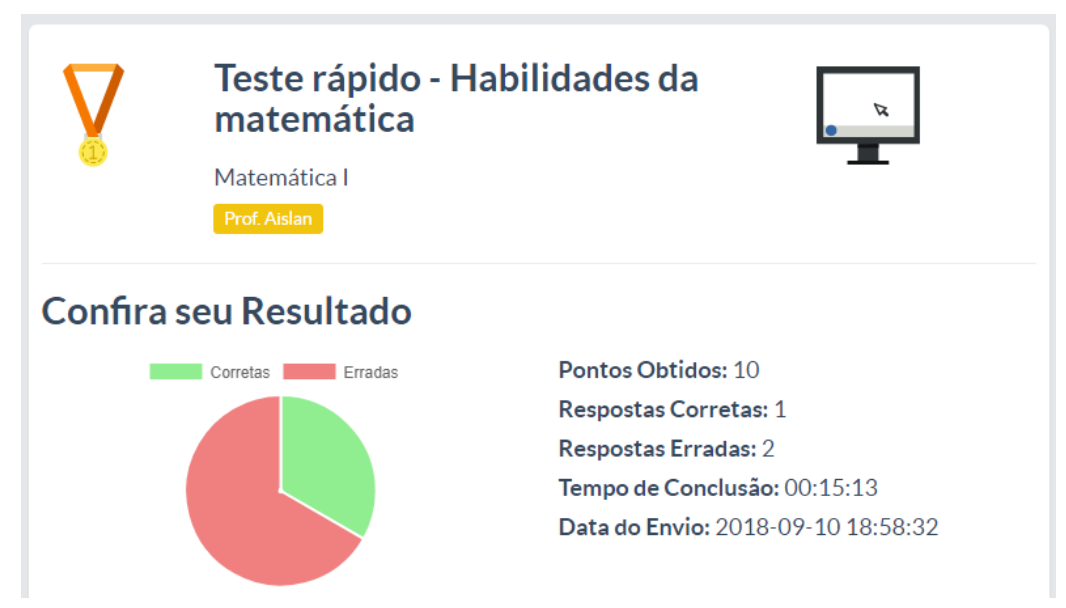

Figura 3. Janela do desempenho do aluno no desafio respondido

Outro elemento da gamificação é a colaboração interativa, que é aplicada ao fórum criado pelo aluno. O quadro de conquistas possui o elemento histórico de objetivos, no qual são expostas todas as conquistas dos alunos. Um elemento que pode ser aplicado fora do ambiente gamificado ProGame são as premiações, por meio das quais o professor pode levar em consideração os resultados obtidos como política de bonificação, como por exemplo, pontos adicionados à média dos alunos ou como atividade complementar. Cada professor pode definir o tipo de premiação mais adequada aos seus alunos.

\section{Avaliação da usabilidade}

Após a construção do ambiente gamificado, 34 alunos de uma turma do $1^{\mathrm{o}}$ ano do ensino médio da Escola Estadual de Educação Profissional Dr. José Iran Costa, localizada na cidade de Várzea Alegre - Ceará, receberam credenciais (logins e senhas) para acesso ao ambiente e participaram do processo de resolução dos desafios proposto pelos professores. Em seguida, eles responderam a um questionário contendo 10 questões sobre usabilidade seguindo os padrões sugerido por [Padilha et al. 2004].

A Figura 4(a) exibe um gráfico sobre os resultados coletados dos 34 alunos da turma que realizaram o teste. Do total de alunos, 29 (85.3\%) concordaram que gostariam de utilizar a ferramenta com frequência, retratando que o ambiente gamificado possui elementos que fazem com que os alunos sintam-se mais à vontade com os recursos dispostos. A Figura 4(b) apresenta o resultado da pergunta sobre complexidade do sistema. $76.5 \%$ dos alunos afirmaram que o ProGame não é complexo. A terceira pergunta representada na Figura 4(c) indagava sobre facilidade do sistema, para qual 28 alunos (82.3\%) concordaram que a plataforma gamificada é de fácil uso. 


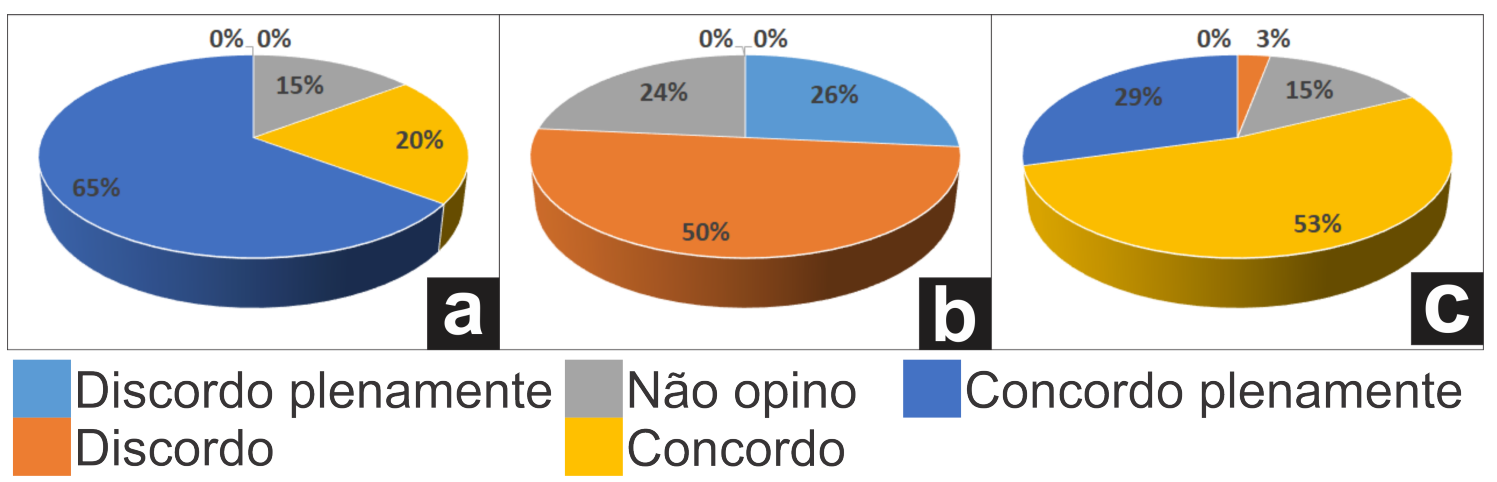

Figura 4. (a) Eu acho que gostaria de usar esse sistema com frequência. (b) Eu acho o sistema desnecessariamente complexo. (c) Eu achei o sistema fácil de usar.

Já em relação à quarta pergunta, cujas respostas são mostradas no gráfico da Figura 5(a), apenas 7 alunos (29.5\%) consideraram a importância de possuir conhecimentos mais específicos para utilizar o ambiente gamificado. O quinto questionamento discorria sobre integração entre as funções do sistema. Alguns dos alunos (88.2\%) concordam que as ferramentas propostas no ProGame apresentam uma boa integração, tornando-os os satisfeitos em utilizar o ambiente, conforme apresentado na Figura 5(b). Os resultados obtidos sobre a pergunta de número 6, ilustrados na Figura 5(c), alertam para possíveis problemas no sistema, pois $55.9 \%$ dos alunos concordaram que o ambiente apresenta inconsistências. O sistema será reanalisado para verificar esse resultado.

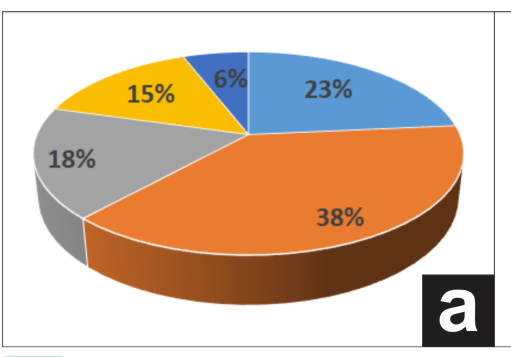

\section{Discordo plenamente Discordo}

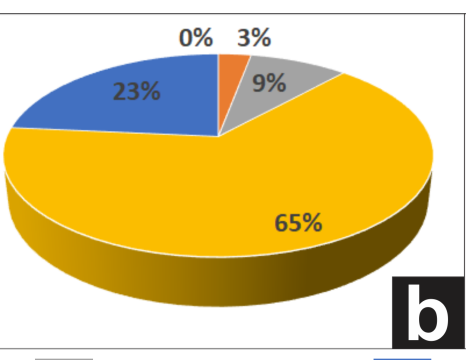

Não opino Concordo

Figura 5. (a) Eu acho que precisaria de ajuda de uma pessoa com conhecimentos técnicos para usar o sistema. (b) Eu acho que as várias funções do sistema estão muito bem integradas. (c) Eu acho que o sistema apresenta muita inconsistência.

Conforme apresentado na Figura 6(a), 29 alunos (85.3\%) declaram que futuros usuários poderão aprender rapidamente o funcionamento da plataforma gamificada. A Figura 6(b) corrobora os resultados da pergunta 4(c), na qual $82 \%$ dos alunos afirmaram que o sistema não é difícil de usar. A proposta ofertada pelo ambiente gamificado apresenta um elevado grau de satisfação entre os alunos participantes da pesquisa (74\%), conforme mostrado na Figura 6(c), o que ressalta a confiabilidade depositada pelos alunos ao utilizar o ambiente gamificado. Por fim, a Figura 6(d) possui uma relação com o enuciado da Figura 5(a), as duas apresentam a necessidade de aprender algo a mais para 
VIII Congresso Brasileiro de Informática na Educação (CBIE 2019)

Anais dos Workshops do VIII Congresso Brasileiro de Informática na Educação (WCBIE 2019)

utilizar o ProGame. Do total de respondentes, $57 \%$ dos afirmaram que não precisaram aprender coisas novas antes de usar o sistema.

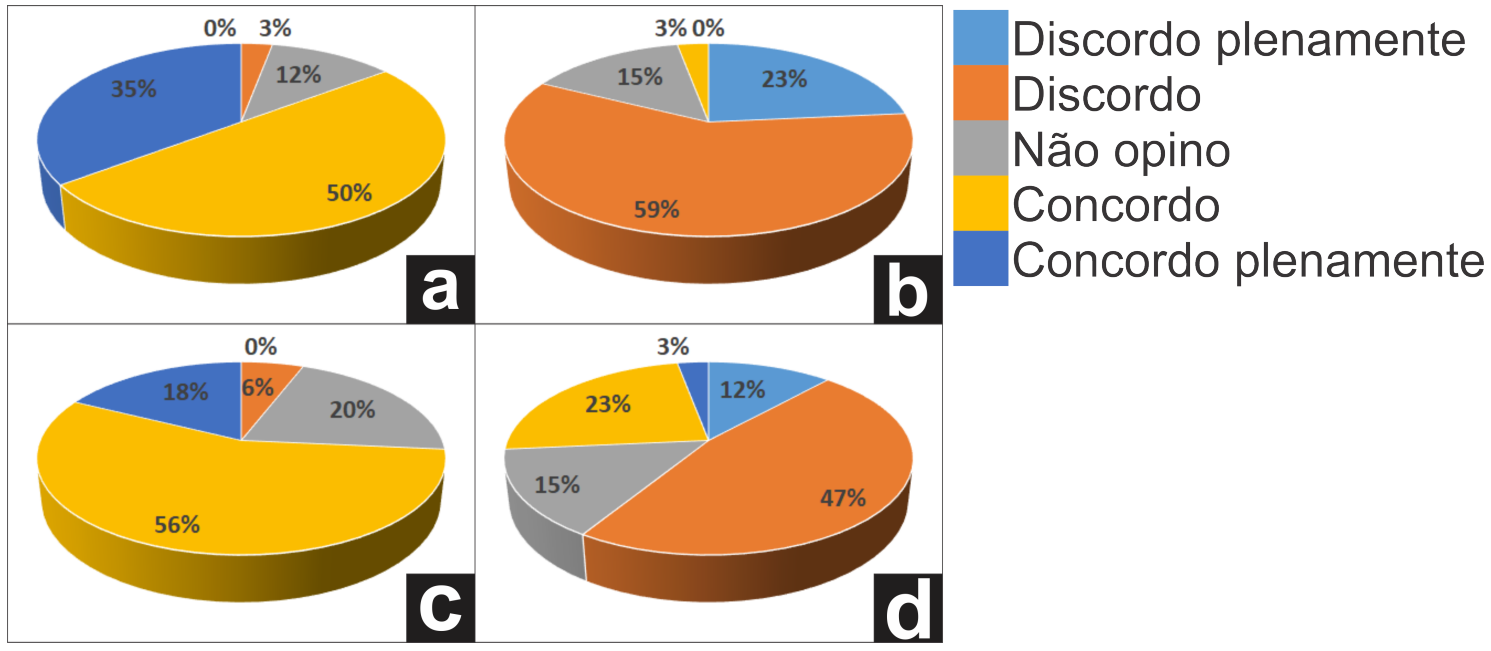

Figura 6. (a) Eu imagino que as pessoas aprenderão como usar esse sistema rapidamente. (b) Eu achei o sistema difícil de usar. (c) Eu me senti confiante ao usar o sistema. (d) Eu precisei aprender várias coisas novas antes de conseguir usar o sistema.

\section{Conclusão}

Utilizar das técnicas disponíves de elementos da gamificação para promover uma alternativa no processo de ensino-aprendizagem dos alunos do ensino médio pode ter efeitos significativos, tendo em vista que a maioria dos jovens gosta de desafios ou de algo que possa favorecer competitividade. A competitividade salutar, em um ambiente de aprendizagem, poderá lhe render bons frutos, pois estimula uma maior interação do aluno com a plataforma, fazendo-o estudar e praticar mais os assuntos abordados, gerando uma possível melhoria no seu desempenho escolar.

Este trabalho apresentou um ambiente gamificado, chamado ProGame, para auxiliar no processo de aprendizagem dos alunos da $1^{\mathrm{a}}$ série do ensino médio com foco nos descritores de matemática do SPAECE. O ambiente gamificado foi testado com 34 alunos, que responderam a um questionário de usabilidade. Pelos resultados, nota-se que a maioria dos alunos pretende usar o ambiente gamificado com frequência e afirma que o sistema é de fácil uso, sem necessidades de conhecimentos adicionais.

\section{Referências}

Alves, F. (2015). Gamification: Como criar experiências de aprendizagem engajadoras. DVS Editora.

Borges, S. d. S., Reis, H. M., Durelli, V. H. S., Bittencourt, I. I., Jaques, P. A., and Isotani, S. (2013). Gamificação aplicada à educação: Um mapeamento sistemático. In XXIV Simpósio Brasileiro de Informática na Educação (SBIE 2013), pages 234-243.

Fardo, M. L. (2014). A gamificação como estratégia pedagógica: estudo de elementos dos games aplicados em processos de ensino e aprendizagem. 
VIII Congresso Brasileiro de Informática na Educação (CBIE 2019)

Anais dos Workshops do VIII Congresso Brasileiro de Informática na Educação (WCBIE 2019)

Moratori, P. B. (2003). Por que utilizar jogos educativos no processo de ensino aprendizagem. UFRJ. Rio de Janeiro.

Neto, A., da Silva, A. P., and Bittencourt, I. I. (2015). Uma análise do impacto da utilização de técnicas de gamificação como estratégia didática no aprendizado dos alunos. In Brazilian Symposium on Computers in Education (Simpósio Brasileiro de Informática na Educação-SBIE), volume 26, pages 667-678.

Padilha, A. V. et al. (2004). Usabilidade na web: uma proposta de questionário para avaliação do grau de satisfação de usuários do comércio eletrônico.

Seixas, L. d. R., Gomes, A. S., Filho, I. J. M., and Rodrigues, R. L. (2014). Gamificação como estratégia no engajamento de estudantes do ensino fundamental. In $X X V$ Simpósio Brasileiro de Informática na Educação (SBIE 2014), pages 559-568. 